\title{
ANÁLISE DO PARQUE DO POVO COMO AGENTE DA REURBANIZAÇÃO DO FUNDO DE VALE, E DESENVOLVIMENTO DA CIDADE DE PRESIDENTE PRUDENTE-SP
}

\author{
Layssa Gabriela Rodrigo Frazili; Sara Lidiane Alves'; Mayara Pissutti Albano²; Yeda Ruiz \\ Maria².
}

1Discente do curso de Arquitetura e Urbanismo da Universidade do Oeste Paulista - UNOESTE. ${ }^{2}$ Arquiteta e Urbanista, Docente do curso de Arquitetura e Urbanismo da Universidade do Oeste Paulista - UNOESTE

\section{RESUMO}

Este artigo visa analisar questões sobre a produção do espaço urbano em Presidente Prudente SP, tendo como foco o Parque do Povo, resultado do processo de urbanização e canalização do trecho do Córrego do Veado, localizado na região Sudeste da cidade. Observando que, o que antes era considerado um entrave ao desenvolvimento da cidade, graças à reurbanização praticada e à desapropriação dos moradores da região para a implantação do parque, hoje é possível notar tamanha valorização tanto da área do parque, como do seu entorno e também o desenvolvimento de tal região. Pesquisas bibliografias e documental embasam a presente pesquisa.

Palavras-chave: espaço urbano; Parque do Povo; urbanização; desenvolvimento.

\section{INTRODUÇÃO E OBJETIVOS}

A presença de políticas públicas como elemento de criação de espaços e áreas urbanas é sentida em diversos setores, principalmente em áreas de recreação. Segundo SANTOS (1978; apud SILVA, 1994) "O espaço é uma forma durável que se desfaz paralelamente à mudança dos processos; ao contrário, alguns processos se adaptam às formas preexistentes, enquanto outros criam novas formas". O destino dos investimentos para a criação destas áreas pode ser influenciada por interesses particulares, que determinarão a "valorização" de um local, em detrimento de outros. De acordo GOTTDIENER(1993) :

[...] a conexão entre valor da localização é um produto social, e o preço pelo uso do espaço, que é expropriado pelos particulares, é percebida quando entendemos o mercado imobiliário como um elo mediador no processo de acumulação de capital. (GOTTDIENER1993; p.180 apud SILVIA,1994; p.108)

Este presente artigo visa discutir a intervenção de políticas públicas na criação de espaços urbanos, tendo como objeto de estudo, o Parque do Povo, localizado na cidade de Presidente Prudente - SP.

O Parque do Povo é um importante marco e referencial urbano, criado na década de 1980, como resultado do processo de urbanização e canalização do trecho do Córrego do Veado. 
Processo que provocou grandes mudanças urbanas, como desapropriação de grande área, substituição de ocupação, especulação imobiliária e mudança de padrão social habitado.

Segundo (HORA \& SILVA, 1992) que para se compreender a configuração espacial da cidade é preciso tentar compreender os processos sociais que geraram esta forma espacial.

\section{METODOLOGIA}

A metodologia seguida está baseada no aprofundamento bibliográfico e documental sobre o histórico de Presidente Prudente, sua origem e desenvolvimento, crescimento populacional sem devido planejamento e possíveis problemas acarretados.

\section{BREVE HISTÓRICO DA FORMAÇÃO DE PRESIDENTE PRUDENTE - SP}

A origem de Presidente Prudente está vinculada à marcha do café rumo ao "sertão" do Estado de São Paulo, motivada pela procura de novas terras, mão de obra imigrante e pela alta dos preços do grão (WHITACKER, 1997).

Tal marcha define-se como sendo ocupação progressiva do interior do estado, tendo como incremento a Estrada de Ferro Sorocabana, que atravessou os sertões do Sudeste em busca do Rio Paraná.

Presidente Prudente iniciou-se a partir de dois núcleos de povoamento, criados para amparar as vendas de terras feitas pelo Cel. Francisco de Paula Goulart e Cel. José Soares Marcondes, responsáveis peça fundação da cidade e sistemática colonização.

Tais núcleos, denominados Vila Goulart e Vila Marcondes, além de funcionar como local de abastecimento de gêneros $e$ instrumentos de trabalho eram atrativos para a fixação de compradores de terras. As posições destes núcleos que ladeavam a estrada de ferro e a própria topografia das áreas tiveram grande importância no desenvolvimento das funções centrais da cidade.

A Vila Goulart, por ter sido implantada anterior à construção da estação ferroviária, influenciou a localização da frente da estação, assumindo características de "centro da cidade", já a Vila Marcondes, por ter sido implantada posteriormente, instalou-se no lado oposto ao da ferrovia, concentrando funções de suporte à ocupação das terras rurais.

Nota-se que até 1960, a expansão urbana de Presidente Prudente dá-se acompanhando a extensão da linha férrea, no sentido norte-sul. A partir de 1970, o crescimento urbano concentrase no sentido leste-oeste, predominando a porção oeste, acompanhando a direção da rodovia 
Raposo Tavares, passando a caracterizar-se pela descontinuidade de implantação de loteamentos, criando vazios que passaram a funcionar como fontes de especulação.

\section{PARQUE DO POVO}

Em 1968 foi implantado em Presidente Prudente, seu primeiro conjunto habitacional, que se deu através da Poupança Continental, financiado pelo Banco Nacional de Habitação (BNH), localizado em uma parte do Jardim Bongiovani, região sul da cidade, denominado Parque Continental. Nesta época, o loteamento Jardim Bongiovani, implantado desde 1962, configuravase como área isolada em função das dificuldades de se atravessar o Córrego do Veado.

Conforme descreve Sposito (1983, p.100):

O bairro era então afastado da cidade nem tanto pela distância, mas muito mais pelas dificuldades de acesso impostas pelo Córrego do Veado. Não havia quaisquer estabelecimentos comerciais e de serviços (como padaria, açougue, sapateiro, bar, por exemplo) que servissem então ao núcleo habitacional. Aos poucos as casas foram sendo abandonadas, passando novamente às mão do BNH. Em 1973, o conjunto foi adquirido do BNH pela imobiliária Roque \& Seabra. A esse tempo a proximidade do Jardim Bongiovani, já com construções de padrão elevado e a notícia de que o vale seria beneficiado, representavam externalidades que promoveram em bem pouco tempo a valorização das casas, antes ocupadas por classes de baixa renda, eram adquiridas depois pela classe média, tanto assim que a maior parte das construções sofreu reformas (ampliações, modernizações, transformações na fachada, etc.).

O Parque do Povo (vide Figura 1) é um exemplo de posicionamento político administrativo adotado pelo poder local na produção de espaço urbano para promoção de "valorização" de uma área específica, nascendo do processo de urbanização e canalização de trecho do Córrego do Veado, localizado na região Sudeste da cidade, através de um projeto denominado "Fundo de Vale" apresentado à população pela Prefeitura Municipal no ano de 1976, sendo este justificado pela "necessidade de reurbanização do fundo de vale, o qual se apresentava como entrave ao desenvolvimento da cidade" (BORTOLO, 2012, p.42). 


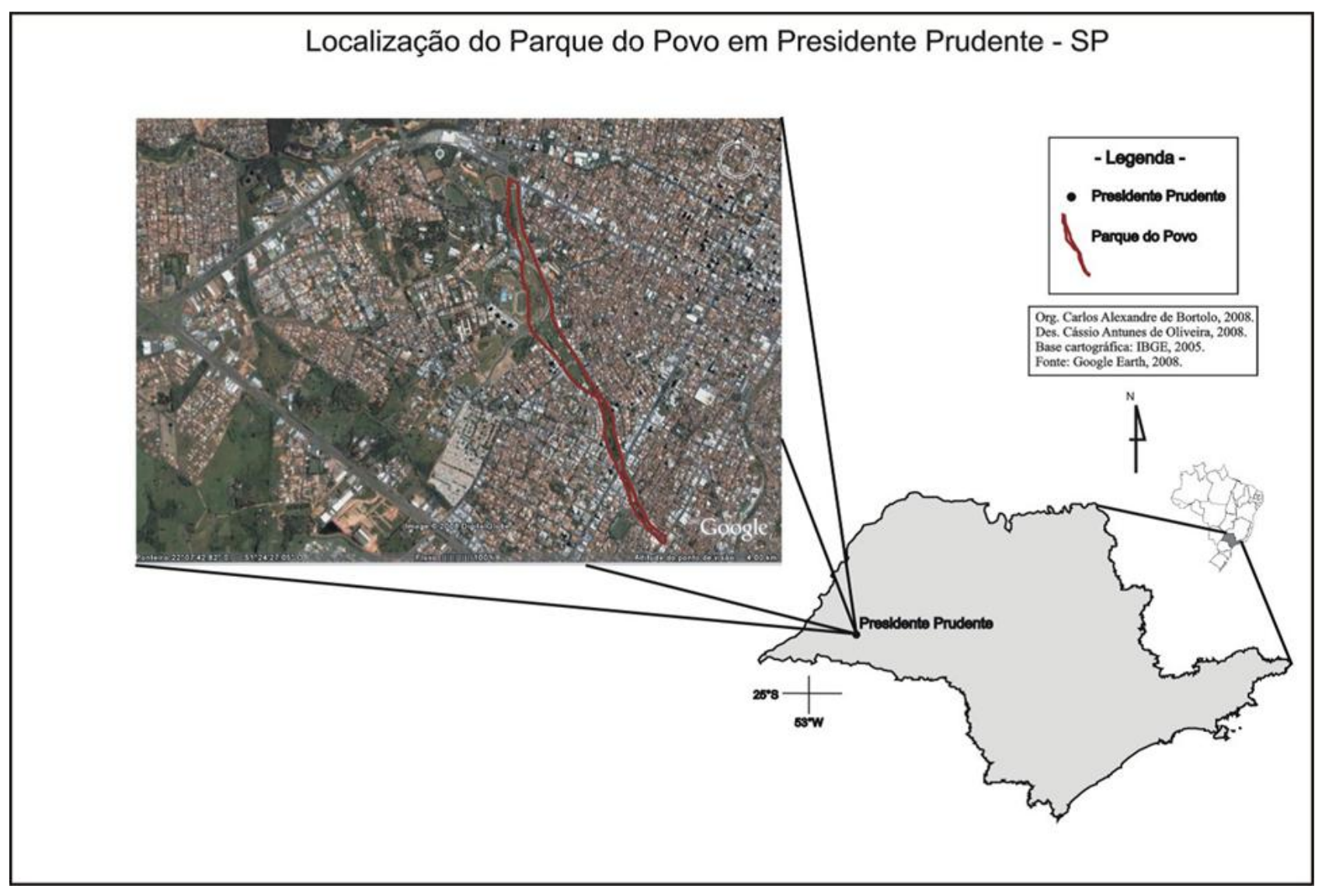

Figura 1. Localização do Parque do Povo em Presidente Prudente.

Fonte: BORTOLO, 2012, p. 43.

A área inicial de abrangencia do projeto era de apoximadamente $460 \mathrm{mil} \mathrm{m}^{2}$ (BORTOLO, 2012). E incluia a canalização do Córrego do Veado no trecho compreendido entre as Avenidas Brasil e Manoel Goulart, assim como a instalação de equipamentos de lazer, pista de atletismo, serviços, duas vias de transito rápido e áreas verdes (Figura 2) (BORTOLO, 2012).

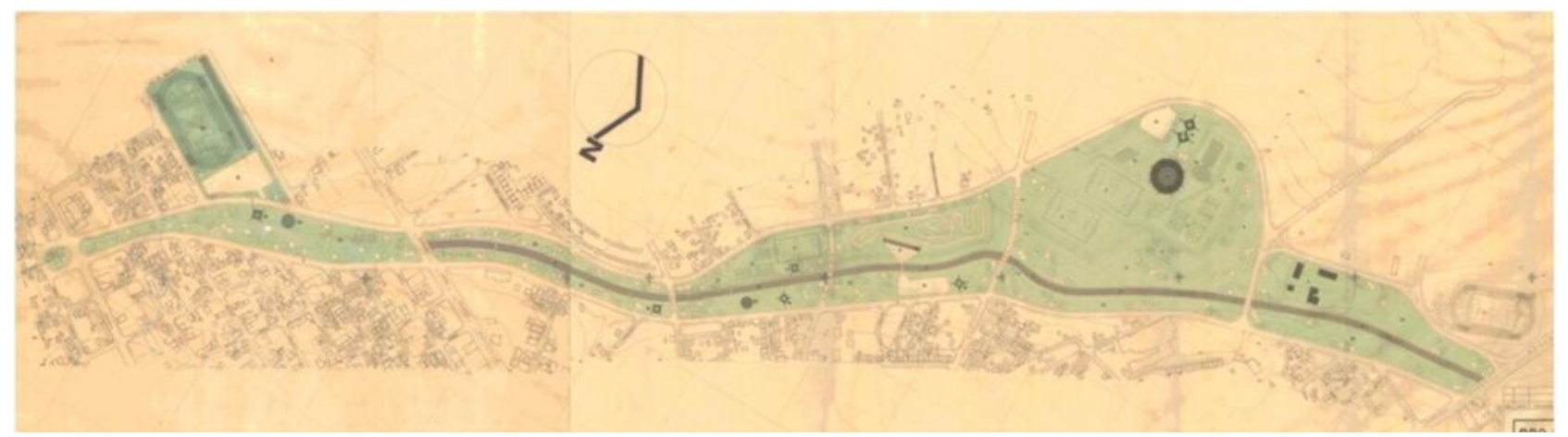

Figura 2. Anteprojeto de Urbanização do Fundo de Vale do Córrego do Veado.

Fonte: Museu e Arquivo Histórico Prefeito Antônio Sandoval Neto, Presidente Prudente - SP apud BORTOLO, 2012, P.46. 
No entanto, quando foi inaugurado em 1982, apenas parte do projeto inicial foi executada. Mas foi o suficiente para provocar grandes mudanças na ocupação urbana, como exemplo, a valorização das áreas adjacentes ao Parque, especulação imobiliária, desapropriação dos moradores do local, criação de vias de acessos, entre outras mudanças.

\section{EXPANSÃO URBANA NA REGIÃO SUDOESTE}

Na cidade de Presidente Prudente a expansão urbana em direção a região Sudoeste sucedeu-se principalmente nas décadas de 70 e 80 . Sendo intensificada e valorizada após a implantação de um programa de reurbanização de uma área degradada e canalização do Córrego do Veado, somado à investimentos em saneamento e melhorias no sistema viário (HORA \& SILVA, 1992).

Esses investimentos ocorridos no local através do Poder Público Municipal com recursos oriundos do Governo Federal geraram grande transformação na região sudoeste da cidade. (HORA \& SILVA, 1992) Sucedendo uma rápida valorização da área, chegando a inverter o eixo de maior demanda de lotes e de status social, até então situados ao "norte da Avenida Washington Luiz para os localizados ao longo do Parque do Povo" (HORA \& SILVA, 1992).

Ao investir nessa área, o poder público remanejou usos e padrões ocupacionais, renovou-os, intensificando a ocupação do solo urbano por segmentos sociais de maior poder aquisitivo, através dos recursos do programa CURA. Tais iniciativas instigaram novas oportunidades de investimentos, visando benefícios aos proprietários e agentes imobiliários. (SILVA, 1994, p.125 apud MINÕ, 2004 p.133)

Essa demanda abrangeu outros loteamentos adjacentes aos localizados ao longo Parque do Povo, e induziu também a especulação imobiliária. Esses fatores associados à implantação do Projeto resultaram num aumento no preço da terra, "trazendo como consequência uma mudança de população que começa a se efetivar a partir de 1978" (HORA \& SILVA, 1992), além da desapropriação do local, uma vez que era ocupado por famílias de baixa renda. Favorecendo assim, os grandes proprietários de terras na região. (BORTOLO, 2012)

A nova paisagem e os novos usos viabilizados pela implantação do Parque do Povo propiciam o acesso por aqueles com poder aquisitivo que permite fazer opção por boas localidades o que inclusive garante a apreensão de alugueis mais elevados, aumentando a especulação acerca destes preços em função daqueles que possuem interesses em residir na área, por tal, estão dispostos a pagar. (SILVA, 1994, p.109) 
A materialização do investimento público, na criação de um espaço urbano, o Parque do Povo, não somente viabilizou a reurbanização da área como também provocou grandes mudanças na ocupação do entorno. Uma vez que estimulou investimentos privados, não somente referente ao mercado residencial, como também comercial e de prestação de serviços ao longo das avenidas que o circundam (BORTOLO, 2004). Ressaltando assim a geração e preservação de espaço privilegiado, estimulando ainda o interesse por áreas próximas (SILVA, 1994).

Sendo observada na implantação alguns loteamentos e edifícios residenciais no segmento de alto poder aquisitivo após/durante a revitalização do Parque, sendo exemplificado pelo loteamento fechado, Jardim João Paulo II (1980), e do bairro de alto padrão Jardim Marupiara (1980), assim como a construção de prédios residenciais, comércios e serviços (MINÕ, 2004).

\section{ESTUDO DE CASO - PARQUE DO POVO}

Segundo o Zoneamento Municipal o entorno imediato do Parque do Povo são áreas de ocupação do tipo ZR3, ZR2 e Zona Especial. Na ZR2, é permitida a ocupação vertical, de até dois pavimentos, e ocupação horizontal de média densidade, na ZR3 é permitida a ocupação vertical de alta densidade, e de interesse social, a Zona Especial (12) é caracterizada por área de recreação e lazer.



\section{ZE - Zona Especial}

ZR 2 - Zona Residencial de média densidade populacional de ocupação horizontal

ZR 3 - Zona Residencial de Alta densidade Populacional de Interesse social e ocupação horizontal e vertical

Figura 4. Mapa de Uso e Ocupação de solo - Presidente Prudente.

Fonte: Site da Prefeitura Municipal de Presidente Prudente. 
O Parque é circundado por vias de transito rápido, Av. 14 de Setembro e 11 de Maio, que conectam as Avenidas Brasil, Cel. Marcondes, da Saudade, Manoel Goulart, Celestino Figueiredo conectando o centro comercial da cidade aos bairros residenciais.

Ao longo das avenidas que o margeiam, há diversos tipos de comércios e serviços, além de edifícios residenciais de múltiplos pavimentos agregando maior fluxo de veículos ao local, somando ao tráfego relacionado aos setores comerciais e residenciais que as avenidas conectam.

Segundo BORTOLO (2012), no projeto estava previsto o plantio de mais de 60 mil árvores no Parque do Povo, além da cobertura rasteira. Na década de 1990 foi realizada a substituição da canalização, atém então trapezoidal, pela canalização fechada constituída por tubos armicos corrugados (BORTOLO, 2012). No ano de 2002, o Parque iniciou-se um processo de revitalização onde foram efetuadas obras em diferentes áreas, sendo estas executadas em etapas, no decorrer dos anos seguintes (MINÕ, 2004).

Em relação à contribuição ambiental do Parque à cidade, segundo Amorim (2005) apesar da grande área coberta por vegetação rasteira e arbórea, fluxo intenso de veículos e o uso do solo nas avenidas que margeiam o fundo de vale, com adensamento de edifícios com usos comercial e residencial, fizeram com que as temperaturas permanecessem elevadas (AMORIM, 2005). Assim como a maioria dos córregos canalizados em diversos pontos da cidade, no período noturno não provocam a "quebra" da ilha de calor ${ }^{1}$ principal existente na cidade (AMORI, 2005).

A ocupação do Parque pelos usuários dar-se de modo diversificado, variando entre lazer, circulação, comercio entre outros. Segundo Silva (1994) os usuários dessa área de lazer são oriundos de diversas partes da cidade, em levantamento realizado por Ribas(1993 apud SILVA 1994, p.113) apenas 13,3\% dos frequentadores do Parque deslocam-se de bairros periféricos ou distantes do local para utiliza-lo como área de lazer. Os $86,7 \%$ restantes são procedentes de áreas centrais ou próximas ao Parque (Gráfico 1). E ainda segundo Silva (1994) Embora residam nas proximidades, 30\% destes chegam ao Parque de automóvel particular.

Conclui-se que, apesar do Parque do Povo ser conhecido como uma área de lazer que atende a toda a população, segundo esses dados, fica evidente que os usuários desse espaço são predominantemente do entorno imediato, não atendendo a toda a população efetivamente como uma área de lazer. Mas não deixa de ser um marco e referência na cidade, além de um importante

\footnotetext{
1 Ilha de calor é um fenômeno climático que ocorre a partir da elevação da temperatura de uma área urbana se comparado a uma zona rural, por exemplo. Isso quer dizer que nas cidades, especialmente nas grandes, a temperatura é superior a de áreas periféricas, consolidando literalmente uma ilha (climática).[Fonte: http://www.brasilescola.com/geografia/ilha-de-calor.htm acessado dia 13/06/2013]
} 
provedor e gerador de diferentes apropriações do espaço urbano, viabilizando a "valorização" do entorno.

\section{CONSIDERAÇÕES FINAIS}

Ao fim deste breve estudo, notou-se a importância de intervenções públicas na criação de espaços urbanos, podendo ser eles de lazer ou não, considerando que esses mesmos espaços podem ser geradores de mudanças em grande escala dentro do perímetro urbano, como é o caso do Parque do Povo, estudado acima, que além de proporcionar tamanha mudança na cidade e na área onde se implantou, modificou também seu entorno. E através dos usos predominantes na região, tal intervenção baseia-se como um elemento de valorização, atingindo o entorno e adjacentes, através da criação de um marco na cidade e referência de espaço público.

\section{REFERÊNCIAS}

AMORIM, Margarete Cristiane de Costa Trindade. INTENSIDADE E FORMAS DA ILHA DE CALOR URBANA EM PRESIDENTE PRUDENTE/SP: EPISÓDIOS DE INVERNO. Artigo Publicado na Geosul, Florianópolis, v. 20, n. 39, p 65-82, jan./jun. 2005

BORTOLO, C. A. (ABRIL de 2012). TRANSFORMAÇÕES NO/DO ESPAÇO URBANO E A DINÂMICA DA PRODUÇÃO DE ESPAÇO PÚBLICO: UM ENSAIO SOBRE O PARQUE DO POVO EM PRESIDENTE PRUDENTE - SP. Maringá, PR, Brasil: Universidade Estadual de Maringá.

HONRA, M. F., \& SILVA, M. M. (1992). (Re)Estruturação da cidade. O PAPEL EXERCIDO PELO PODER PÚBLICO NO PROCESSO DE “VALORIZAÇÃO” DE ÁREAS URBANAS. O PARQUE DO POVO EM PRESIDENTE PRUDENTE- SP. Presidente Prudente, SP, Brasil: Unesp.

MINÕ, O. A. (2004). Tese de Doutorado. OS ESPAÇOS DA SOCIEDADE SEGMENTADA: A PRODUÇÃO DO ESPAÇO PÚBLICO EM PRESIDENTE PRUDENTE. PRESIDENTE PRUDENTE, SP, BRASIL: UNESP.

SILVA, Maria José Martinelli. O Parque do povo em Presidente Prudente - SP: a lógica da intervenção do poder público local no processo de (re)estruturação do espaço urbano. 1994. 152 f. Dissertação (Mestrado em Geografia) - Faculdade de Ciências e Tecnologia, UNESP. Presidente Prudente.

SPÓSITO, M.E.B. O ‘chão’ em Presidente Prudente: a lógica da expansão territorial urbana. São Carlos: IGCE/UNESP, 1983 (Dissertação de Mestrado).

STIPP, N. A., \& Marcelo Eduardo Freres STIPP. (JULIO/DEZEMBRO de 2004). ANÁLISE AMBIENTAL EM CIDADES DE PEQUENO E MÉDIO PORTE. LONDRNA, PARANÁ, BRASIL: UEL.

TAKENAKA, E. M. (2008). Tese de Doutorado. POlíticas PÚblicas DE GeRENCIAMENTO INTEGRADO DE RESÍDUOS SÓLIDOS URBANOS NO MUNICÍPIO DE PRESIDENTE PRUDENTE-SP. 
Encontro de Ensino, Pesquisa e Extensão, Presidente Prudente, 21 a 24 de outubro, 2013

Presidente Prudente, São Paulo, Brasil: Geografia da Faculdade de Ciências e Tecnologia da Universidade Estadual Paulista - UNESP.

WHITACKER, M. A. A PRODUÇÃO DO ESPAÇO URBANO EM PRESIDENTE PRUDENTE: UMA DISCUSSÃO SOBRE A CENTRALIDADE URBANA (1997). 301 f. Dissertação de Mestrado. Universidade Estadual Paulista "Júlio Mesquita Filho", Presidente Prudente. 